\title{
Factors Affecting Organizational Citizenship Behavior: A Literature Review
}

\author{
Lila Bismala \\ \{lilabismala@umsu.ac.id\} \\ University of Muhammadiyah Sumatera Utara, Jalan Kapten Mukhtar Basri No. 3 Medan, Indonesia

\begin{abstract}
This article aims to examine the factors that influence organizational citizenship behavior (OCB). OCB relates to the effort used by one employee to do extra things in the organization. OCB can influence organization performance and contribute to organizational successfulness. OCB includes organizational compliance, organizational loyalty and organizational participation. The factors that influence OCB are job satisfaction, leadership, and organizational climate. Through job satisfaction that is felt by employees, effective leadership, and a positive organizational climate, employees will be willing to do more than just formal tasks and deliver performance beyond organizational expectations.
\end{abstract}

Keywords: Organizational Citizenship Behavior, Job Satisfaction, Leadership, Organizational Climate

\section{Introduction}

An organization is a place for individuals as a medium to fulfill their needs, through work. In organizations, of course, humans try to do their work as well as possible and interact with other people. An organization hopes that its members work as well as possible, and will have mutualism symbiosis between the organization and its members. If members work well, the organization will progress. If the organization develops, the results will be used to provide appropriate compensation and rewards for its members. In order to form mutualism symbiosis, there will be mutually beneficial cooperation, where each other needs. It contains interaction among its members, which can be guidance, supervision, and other management activities.

A good organization will be able to regulate all the interactions and activities in it that are carried out by its members This is what is said as management, which is translated as science and art to perform functions effectively and efficiently against existing resources. Management is a process for the achievement of organizational goals by implementing functions in the form of planning, organizing, leadership, and control. Human elements are very important in achieving organizational goals, which supported by other resources.

There are 3 important factors in the study of organizational behavior, such as individuals, groups, and structures. This means that the individuals working together in a group, and for the achievement of goals, the organizational structure is required. The organizational structure seeks to ensure the division of tasks and responsibilities according to expertise, description of each work.

Each employee will produce performance, and performance accumulation will have an impact on organizational performance. Good employee performance will provide good performance for the organization. Employee performance is shaped by various factors 
Succesful organization achieved when employees are willing to do more than just their formal tasks and deliver performance beyond the expectations of the organization. Employees will have a very big commitment to the organization, with a great desire to sacrifice, without expectation of rewards. This is what is known as organizational citizenship behavior. Therefore, it is important to understand how OCB is in the organization. In many studies, OCB was found to influence the effectiveness of the organization. (Mohammad, Habib, \& Alias, 2011)

OCB relates to the effort used by the employee to do additional things in the interests of the organization. Helping coworkers to complete work or provide support during work is a good thing from a superior point of view. OCB has many advantages, such as improving relations between employees, improving organizational performance, increasing job satisfaction, improving performance, etc. It was emphasized that OCB is not the most important part of the performance. (Veličkovska, 2017)

OCB is interesting to study because prosocial behavior is the output of voluntary attitudes that are far from the pragmatism and transactional factors that commonly found in formal organizations, especially profit oriented. In addition, OCB also represents the basic nature of human beings who are socially and helpful, who in the modern era seem to be imprisoned by the capitalist paradigm which requires pragmatism, profit, and individualism.

This study aims to examine the factors influencing OCB. In many studies, it is stated that several factors that influence OCB are job satisfaction, leadership, and organizational climate.

\section{Literature Review}

\subsection{Organizational Citizenship Behavior}

OCB is an extra role that is done based on voluntary feelings. These behaviors include voluntary actions in creativity and innovation designed to improve one's work or organizational performance, persevere with extra enthusiasm and energy to complete one's work, volunteer to take extra responsibility, and encourage others in the organization to do the same. OCB relates to the effort used by one employee to do extra things in the organization. Helping colleagues to complete work or provide support during work. (Veličkovska, 2017)

Dimensions of OCB by Organ (1988) in (Alkahtani, 2015) include:

1. Altruism means the willingness of employees to help others with organizationally relevant tasks (eg volunteering to help less skilled or new employees).

2. Courtesy means preventing problems stemming from work relationships (eg encouraging desperate colleagues in professional development)

3. Sportsmanship implies that employees have a positive attitude and are willing to tolerate less than ideal conditions without complaining.

4. Civic virtue means that employees responsible to participating and care about, the welfare of the company (eg attending meetings that are not needed, providing creative advice for improvement).

5. Conscientiousness is the dedication to work and the desire to exceed formal requirements, in terms of timeliness or resource conservation (eg working all day or maintaining organizational rules).

OCB can contribute to organizational successfulness (Podsakoff, MacKenzie, Paine, \&

Bachrach, 2000):

1. Increase the productivity of colleagues and managerial

2. Free up resources so they can be used for more productive purposes

3. Help coordinate activities both within and across work groups 
4. Strengthen the organization's ability to attract and maintain the best work

5. Improve organizational performance stability

6. Allows organizations to adapt more effectively to environmental changes

Borman and Motowidlo (1993) as cited by (Ebrahimpour, Zahed, Khaleghkhah, \& Sepehri, 2011) mention the trends and attitudes determine the importance of OCB:

1. Global competition in human resources, especially organizational support for substantial internal and employee initiatives, has further increased the importance of OCB.

2. The second factor relates to team-based organizations that require more OCB.

3. Organizational performance and in particular the role of substantial and internal initiatives of employees in reducing staff and streamlining with the aim of adapting to change.

4. Customer service and client satisfaction are increasingly emphasized.

OCB is important because the organization's profit orientation has changed the way employees think. Not many employees can and are able to implement OCB without expecting an award from the organization.

\subsection{Effect Of Job Satisfaction On Organizational Citizenship Behavior}

Job satisfaction refers to the desires or positive feelings that people have towards their work, emotional feelings that are helpful and positive person after performing the task. Lack of job satisfaction causes low staff morale and has a negative effect on organizational productivity. (Talachi, Gorji, \& Bin Boerhannoeddin, 2014) Job satisfaction is a multidimensional concept that includes individual abilities, attitudes, beliefs, and value systems. To achieve job satisfaction, it is important for staff to have the characteristics of positive feelings and attitudes, commitment, and responsibility. In addition, they must have critical thinking, and specific planning to achieve competence and job satisfaction, which are needed to manage and control their satisfaction, and that results in a pleasant feeling, positive attitude, responsibility and accountability to themselves and others. (A. Ravari, T, M, \& A, 2012)

Personal characteristics of workers (demographic variables such as age, sex, education, marital status), and the characteristics of the work itself (such as working hours, income, professional status, activity sector) are variables that explain job satisfaction. (Fiorillo \& Nappo, 2011) Job satisfaction dimensions include salary, promotion, co-workers, supervision, and the work itself. (Basirudin, Basiruddin, Mokhber, Rasid, \& Zamil, 2016)

Employee satisfaction can improve service quality. (Parvin \& Kabir, 2011) Factors that can influence the level of job satisfaction include the level of salaries and benefits, perceived justice from the promotion system in the company, the quality of work conditions, leadership and social relations, the work itself (various tasks involved, interests and challenges generated by the work, and clarity of description / job requirements. (Parvin \& Kabir, 2011) Job satisfaction factors are divided into three dimensions, namely the requirements and benefits of the workforce, status and relationships in the workplace and organizational arrangements. Job satisfaction theory shows a very strong relationship between the age of employees and their relationship to work (satisfaction with aspects of work) (Hajdukov, Klementova, \& jr, 2015 ) To improve employee job satisfaction, it is done through respecting and respecting employees, increasing salaries, increasing knowledge through training, preparing the facilities needed to continue education and also increasing personal relationships and work relationships, etc. to create OCB. (Talachi, Gorji, \& Bin Boerhannoeddin, 2014)

Several studies show a significant relationship between job satisfaction and OCB. (Talachi, Gorji, \& Boerhannoeddin, 2014; Ragel \& Ragel, 2017; Shafazawana, et. All, 2015; Basirudin, Basiruddin, Mokhber, Rasid, \& Zamil, 2016; Tharikh, Ying, Mohamed Saad, \& Sukumaran, 2016) Job satisfaction dimensions include salary, promotion, co-workers, 
supervision, and the work itself, affecting OCB. (Basirudin, Basiruddin, Mokhber, Rasid, \& Zamil, 2016) For example, when employees feel that their organization is attentive to their personal growth, development and progress in their work, they are happy and satisfied with their organization. In addition, they feel obliged to reciprocate by practicing and demonstrating positive attitudes and behaviors that will benefit their organization. (Mohammad, Habib, \& Alias, 2022)

\subsection{Effect of Leadership on Organizational Citizenship Behavior}

An initiative is an intelligent procedure of impact that happens when a few people acknowledge somebody as their pioneer to accomplish a shared objective. (Silva, 2016) This demonstrates:

1. Leadership is a procedure and not simply close to the home quality

2. The initiative process is described by impact, not simply the impact of pioneers on supporters

3. The authority process happens in specific settings

4. The authority process necessitates that individuals, supporters, acknowledge somebody as their pioneer

5. The motivation behind the initiative procedure is to accomplish shared objectives

Leadership with effective skills can help leaders gain the trust of employees, making other tasks easier to operate because employees trust their leaders. Leadership skills also allow leaders to lead employees in the right direction, according to the organization's vision and mission. (Hao \& Yazdanifard, 2015)

The Great Man theory focuses on heroic individuals, implying that only a select few can reach their greatness. Trait theory defines leadership in the universality of attributes given. Skill theory focuses on the ability of a leader. Behavioral theory views leaders based on their actions and behavior, while contingency theory concerns the context of leadership. (Harrison, 2018)

Transformational leadership becomes an effective style for use in the context of R \& D. Inspirational motivation to provide a shared vision for the project allows team members from various disciplines to work together to bring technological innovation to results. In addition, using intellectual stimulation encourage team members from various disciplines to see problems from a new point of view that can increase innovation. (Elkins \& Keller, 2003)

Leadership style, organizational commitment, and job satisfaction are interrelated. The leadership style influences the quality of work life. (Nanjundeswaraswamy \& Swamy, 2014) Transformational leadership style shows greater predictive strength in OCB than transactional leadership. Transformational leaders able to lead their subordinates to take actions that go beyond the specified role, better than transactional. (Rodrigues \& Ferreira, 2015; Khan, Ghouri, \& Marinah Awang, 2013; Malik, et all, 2016; Lian \& Tui (2012) The focus of transformational leaders is directed to the organization, and its behavior builds on followers' commitment to organizational goals, while the focus of the service leader is on followers, and the achievement of organizational goals is the result of subordinates.

The focal point of transformational pioneers is coordinated to the association, and its conduct expands on adherents' duty to authoritative objectives, while the focal point of the administration pioneer is on supporters, and the accomplishment of hierarchical objectives is the aftereffect of subordinates. (Stone, Russell, \& Patterson, 2004) Managers / leaders must try to motivate subordinates to show OCB. (Yasir, 2013) Transactional leaders tend to use influences that emphasize exchange, pressure and legitimacy tactics. Transformational leaders 
tend to use more consulting tactics dealing with subordinates who show a higher level of competence. (Lian \& Tui, 2012)

Democratic leadership stimulates OCB more. Autocratic leaders are not able to stimulate feelings of helping others because of their task-oriented. Laissez faire's leadership style has a very weak relationship with OCB. A leader can play an active role in developing awareness about OCB and guiding employees to engage in extra role behavior. (Malik, et all, 2016)

\subsection{Effect of Organizational Climate on Organizational Citizenship Behavior}

Organizational climate is defined as perceptions, feelings and attitudes of members of an organization about the fundamental elements of an organization, which reflect the norms, values and attitudes of existing organizational culture and influence individual behavior positively or negatively. (Haritha \& S.E.V.Subrahmanyam, 2013) Organizational climate is a combination of the work environment, which is perceived directly or indirectly by employees, which is considered a major force in influencing employee behavior.

Organizational climate is a blend of the workplace, which is seen specifically or in a roundabout way by representatives, which is viewed as a noteworthy power in impacting worker conduct. (Permarupan, Mamun, Saufi, \& Zainol, 2013) Organizational climate is about the lifestyles of people in the organization, and can have a major impact on factors such as productivity, performance and job satisfaction, organizational commitment and behavior, increasing mental energy and increasing staff morale and motivation to learn and change behavior and ultimately affect the success of the organization. (Gholami, Keykale, Tir, Ramandi, Karimi, \& Rajaee, 2015)

Positive organizations climate include job characteristics, empowerment, relationships, performance and rewards, standardization, managerial structure, power and centralization, participation management, conflict resolution, knowledge and innovation, risk taking, welfare and security, teamwork, communication, managerial style, compensation, assessment system. (Haritha \& S.E.V.Subrahmanyam, 2013) There are 6 climate dimensions: clarity, standard, responsibility, flexibility, appreciation, team commitment. Positive climate encourages employee productivity and decreases turnover. (Permarupan, Mamun, \& Ahmad, 2013)

Priority must be given to issues related to innovation, support, employee recognition and autonomy to create a good work climate. Human resource practitioners are encouraged to give gifts to policies and procedures that encourage an employee-friendly work environment that promotes extra performance. (Agyemang, 2013)

A good organizational climate has an impact on improving OCB. (Gholami, Keykale, Tir, Ramandi, Karimi, \& Rajaee, 2015; Pourkiani, Farokhian, \& Gheisari, 2014; Shahin, Naftchali, \& Pool, 2014) OCB in turn has a positive and significant impact on organizational performance. (Shahin, Naftchali, \& Pool, 2014)

The research data analysis technique uses content analysis which intends to analyze the contents of the references to be concluded later. The variables in this study are organizational citizenship behavior, job satisfaction, leadership and organizational climate.

\section{Discussion}

As stated that Organizational Citizenship Behavior is the desire of employees to sacrifice, commit and deliver performance beyond organizational expectations, the OCB provides many benefits to the organization. The main advantage is increased productivity, where employees with high awareness will do their best. Because OCB contains the concept of helping coworkers voluntarily, it can coordinate well. Responsibility, dedication and great 
commitment to his work, even the work of his colleagues will help the organization solve problems.

OCB is influenced by many factors. The factor predicted to affect OCB is job satisfaction. (Talachi, Gorji, \& Boerhannoeddin, 2014; Ragel \& Ragel, 2017; Shafazawana, et. All, 2015; Basirudin, Basiruddin, Mokhber, Rasid, \& Zamil, 2016; Tharikh, Ying, Mohamed Saad, \& Sukumaran, 2016) Employees who are satisfied with their work (due to individual ability factors, attitudes, beliefs, value systems, positive attitudes, commitments, responsibilities, demographic variables such as age, sex, education, marital status, characteristics of the work itself (such as working hours, income, professional status, activity sector), salary, promotion, co-workers, supervision, quality of working conditions, leadership and social relations) of course will be willing to do work and responsibilities beyond its obligations. (Singh \& Jain, 2013) Satisfaction of these factors indicates that the employee has a higher level of achievement. Nothing guarantees that the higher the position in the organization will increase satisfaction, because the position will be accompanied by increasing responsibilities. Initially salary is the first predictor of job satisfaction, but immaterial satisfaction is much more desirable.

The next factor that influences OCB is leadership. (Rodrigues \& Ferreira, 2015; Khan, Ghouri, \& Marinah Awang, 2013; Malik, et all, 2016; Lian \& Tui, 2012; Yasir, 2013) Leadership is related to how to direct subordinates, according to process and behavior. Democratic leaders are preferred. The leader does not need to regulate subordinates too much, because all members of the organization already know their job descriptions. Binding leadership will cause subordinates to be distrustful of leaders, feeling unreliable. Lack of trust between leaders and subordinates causes subordinates to not implement OCB, because what is done on their own initiative can be blamed. Leadership with effective skills (gaining trust from employees), having appropriate attributes, having the ability (beyond the ability of subordinates), being able to motivate employees, is a characteristic of leadership that can grow OCB. Leadership that has influence is a combination of the desire to make a difference, moral authority and actions taken to realize the desire. Leaders who can influence generations have goals, beliefs, moral authority, they lead with passion, commitment, courage and they always learn. (Mango, 2018) Effective basic leadership characters include the character of the leader, practice of human resources, institutional practice, context and results. (Mango, 2018)

A good leader usually has a clear vision for the company and can easily identify current problems and obstacles. Leaders guide employees toward organizational goals, try to communicate and motivate employees to ensure they are in the right position. Some employees may be able to easily adapt to changes but some will resist change; some may accept their leader's way and learn from the actions of leaders, but some will become jealous of their leaders and refuse to cooperate. (Hao \& Yazdanifard, 2015)

Different tasks usually require different patterns of leadership behavior. In addition, subordinates are usually different in terms of their experience, skills, values, and needs, and the behavior of leaders with different individuals must vary. Flexibility is also needed when changes occur from time to time in a subordinate's skills and motives. How well a leader handles crisis and makes change is a flexible and adaptive indicator of leadership. The following is a recommended guide for a leader: (Yukl \& Mahsud, 2010)

1. Learn to diagnose a situation and use relevant contingency theory to identify the type of leadership behavior that is appropriate for each type of situation.

2. Increase flexibility by learning how to use various relevant behaviors;

3. Proactively influence aspects of the situation to create a substitute for leadership; for example improving the selection of competent subordinates to reduce supervision 
Interpersonal leadership categories consist of personal attributes. communication competence, supporting others. Fostering and maintaining good relationships, managing conflicts, understanding, caring, and considering others, fostering happiness, motivating others, delegating and empowering, promoting collective decision making. develop others. encourage innovative thinking, respect and recognize others. (Lamm, Carter, \& Lamm, n.d.)

OCB is also influenced by the organizational climate. (Gholami, Keykale, Tir, Ramandi, Karimi, \& Rajaee, 2015; Pourkiani, Farokhian, \& Gheisari, 2014; Shahin, Naftchali, \& Pool, 2014) A positive organizational climate includes job characteristics, empowerment, relationships, performance, and rewards, standardization, managerial structure, power, and centralization, participation management, conflict resolution, knowledge and innovation, risk taking, welfare and security, teamwork, communication, managerial style, compensation, a fair assessment system, is the cause of the implementation of OCB by employees. A positive climate gives employees a sense of comfort, feels they have an organization and ultimately causes employees to deliver performance beyond their duties and responsibilities.

The most common management problems faced by organizations today are a flexible work environment that causes job satisfaction and innovation. Climate has a real effect on employee motivation. A good work climate increases employee morale, loyalty, and productivity. (Permarupan, Mamun, \& Ahmad, 2013)

\section{Conclusion}

a. Job satisfaction with indicators individual abilities, attitudes, beliefs, value systems, positive attitudes, commitments, responsibilities, demographic variables such as age, gender, education, marital status, characteristics of the work itself (such as working hours, income, professional status, activity sector), salary, promotion, co-workers, supervision, quality of work conditions, leadership, and social relations, affect OCB

b. Leadership, with indicators having goals, beliefs, moral authority, leading with enthusiasm, commitment, courage and they always learn, effective skills (gain trust from employees), have appropriate attributes, have the ability (beyond the ability of subordinates), are able motivate employees, influence OCB

c. Positive organization climate includes job characteristics, empowerment, relationships, performance, and rewards, standardization, managerial structure, power and centralization, participation management, conflict resolution, knowledge and innovation, risk taking, welfare and security, teamwork, communication, style managerial, compensation, fair valuation systems, influence on OCB

\section{References}

[1] A, R., T, M., M, K., \& A, J. (2012). Job satisfaction as a multidimensional concept: A systematic review study. JOHE, Summer 1 (2), 95-102.

[2] Agyemang, C. B. (2013). Perceived Organizational Climate and Organizational Tenure on Organizational Citizenship Behaviour: Empirical Study Among Ghanaian Banks. European Journal of Business and Management Vol.5, No.26, 132-143.

[3] Alber. (2016). What is Leadership? Journal of Business Studies Quarterly Vol 8 Number 1, 1-5.

[4] Alkahtani, A. (2015). Organizational Citizenship Behavior (OCB) and Rewards. International Business Research Vol 8(4) , 210-222. 
[5] Basirudin, N. B., Basiruddin, R., Mokhber, M., Rasid, S. Z., \& Zamil, N. A. (2016). Organizational Citizenship Behaviour in Public Sector: Does Job Satisfaction Play a Role. International Journal of Economics and Financial Issues, 6(S8), 376-381.

[6] Christophersen, K.-A., Elstad, E., Solhaug, T., \& Turmo, A. (2015). Explaining Motivational Antecedents of Citizenship Behavior among Preservice Teachers. education sciences, 5, , 126-145.

[7] Ebrahimpour, H., Zahed, A., Khaleghkhah, A., \& Sepehri, M. B. (2011). A survey relation between organizational culture and organizational citizenship behavior. Procedia - Social and Behavioral Sciences 30, 1920 - 1925.

[8] Elkins, T., \& Keller, R. T. (2003). Leadership in research and development organizations: A literature review and conceptual framework. The Leadership Quarterly 14, 587-606.

[9] Fiorillo, D., \& Nappo, N. (2011, 6 -). Job satisfaction in Italy:Individual characteristics and social relations. Health, Econometrics And Data Group, pp. 1-32.

[10] Gholami, S., Keykale, M. S., Tir, M., Ramandi, F. D., Karimi, M., \& Rajaee, R. (2015). Investigation The Relationship Between Organizational Climate And Organizational Citizenship Behavior Vamong Staff In Hospital. International Journal of Public Heath, Pharmacy and Pharmacology Vol.1, No.1 June, 14-22.

[11] Hajdukov, A., Klementova, J., \& Jr, J. K. (2015 ). The job satsfaction as regulatorof the working behavior. Procedia - Social and Behavioral Sciences 190 , 471 - 476.

[12] Hao, M. J., \& Yazdanifard, R. (2015). How Effective leadership can Fasilitate Change In Organization Through Improvement and Innovation. Global Journal of Management And Business Research volume XV Issue IX Version I, 1-6.

[13] Haritha, K., \& S.E.V.Subrahmanyam. (2013). Organisational Climate: An Empirical Investigation In PennaCement Industries Limited (PCIL). International Journal of Business and Management Invention Vol 2 Issue 12 Desember, 12-20.

[14] Harrison, C. (2018). Leadership Theory and Research: A critical Approach to New And Existing Paradigm. -: Springer.

[15] Khan, N. R., Ghouri, A. M., \& Marinah Awang. (2013). Leadership Styles And Organizational Citizenship Behavior In Small And Medium Scale Firms. International Refereed Research Journal Vol.- IV, Issue , 144-154.

[16] Kundu, K. (2007). Development Of The Conceptual Framework Of Organizational Climate. Vidyasagar University Journal of Commerce Vol. 12, March, 99-108.

[17] Lamm, K. W., Carter, H. S., \& Lamm, A. J. (n.d.). A Theory Based Model of Interpersonal Leadership: An Integration of the Literature. Journal of Leadership Education, 15 (4), 183-205.

[18] Lian, L. K., \& Tui, L. G. (2012). Leadership Styles and Organizational Citizenship Behavior: The Mediating Effect of Subordinates' Competence and Downward Influence Tactics. Journal of Applied Business and Economics vol. 13 (2), 59-96.

[19] MALIK, S. Z., SALEEM, M., \& NAEEM, R. (2016). EFFECT OF LEADERSHIP STYLES ON ORGANIZATIONAL CITIZENSHIP BEHAVIOUR IN EMPLOYEES OF TELECOM SECTOR IN PAKISTAN. Pakistan Economic and Social Review Volume 54, No. 2 (Winter), 385-406.

[20] Mango, E. (2018). Beyond Leadership. Open Journal of Leadership 7, 117-143.

[21] Mango, E. (2018). Rethinking Leadership Theories . Open Journal of Leadership 7 , 57-88. 
[22] Mohammad, J., Habib, F. Q., \& Alias, M. A. (2022). Job Satisfaction And Organisational Citizenship Behaviour: An Empirical Study At Higher Learning Institutions. Asian Academy of Management Journal, Vol. 16, No. 2, 149-165.

[23] Mushraf, A. M., Al-Saqry, R., \& Obaid, H. J. (2015). The Impact of Big Five Personality Factors on Organizational Citizenship Behaviour. International Journal of Management Science; 2(5), 93-97.

[24] Parvin, M. M., \& Kabir, M. M. (2011). Factors Affecting Employee Job Satisfaction Of Pharmaceutical Sector. Australian Journal of Business and Management Research vol 1 No 9, 113-123.

[25] Permarupan, P. Y., Mamun, A. A., Saufi, R. A., \& Zainol, N. R. (2013). Organizational Climate on Employees' Work Passion: A Review. Canadian Social Science Vol. 9, No. 4, , 63-68.

[26] Pourkiani, M., Farokhian, A., \& Gheisari, F. (2014). Explaining The Relationship Between Organizational Climate, Organizational Commitment And Organizational Citizenship Behavior Among Employees Of Khuzestan Gas Company. Indian Journal of Fundamental and Applied Life Sciences Vol. 4, 292-290.

[27] Ragel, S., \& Ragel, V. R. (2017). The Effects of Job Rotation, Role Stress and Job Satisfaction on Organizational Citizenship Behavior of Bank Employees. Asian Journal of Economics, Business and Accounting 4, 1-10.

[28] Ramezani, S., Roohazad, A., Alizadeh, Z., \& Amiri, S. R. (2015). Identification And Ranking Of The Factors Affecting The Development Of Organizational Citizenship Behavior A Case Study Of National Iranian Oil Products Distribution (NIOPDC), TEHRAN, IRAN. International Journal of Economics, Commerce and Management Vol. III, Issue 5, May, 1138-1154.

[29] Rodrigues, A. d., \& Ferreira, M. C. (2015). The Impact of Transactional and Transformational Leadership Style on Organizational Citizenship Behaviors. PsicoUSF, Bragança Paulista, v. 20, n. 3 , 493-504.

[30] Shafazawana, Tharikh, M., Ying, C. Y., Zuliawati, Saad, M., \& Sukumaran, K. (2015). Managing Job Attitudes: The Roles of Job Satisfaction and Organizational Commitment on Organizational Citizenship Behaviors. 7th International Economics \& Business Management Conference (pp. 604 - 611). -: Procedia Economics and Finance 35 (2016)

[31] Shahin, A., Naftchali, J. S., \& Pool, J. K. (2014). Developing a model for the influence of perceived organizational climate on organizational citizenship behaviour and organizational performance based on balanced score card. International Journal of Productivity and Performance Management, Vol. 63 Issue: 3 , 290-307.

[32] Silva, A. (2016). What is Leadership? Journal of Business Studies Quarterly Vol 8 No $1,1-5$.

[33] Singh, J. K., \& Jain, M. (2013). A STUDY OF EMPLOYEES'JOB SATISFACTION AND ITS. Journal of Indian Research, 1(4), 105-111.

[34] Stone, A. G., Russell, R. F., \& Patterson, K. (2004). Transformational versus servant leadership: a difference in leader focus. Leadership \& Organization Development Journal Vol 25 Issue 4 , 349-361.

[35] Talachi, R. K., Gorji, M. B., \& Boerhannoeddin, A. B. (2014). An Investigation of the Role of Job Satisfaction in Employees' Organizational Citizenship Behavior . Coll. Antropol. 38 (2), 429-436

[36] Tharikh, S. M., Ying, C. Y., Mohamed Saad, Z., \& Sukumaran, K. a/p. (2016). Managing Job Attitudes: The Roles of Job Satisfaction and Organizational 
Commitment on Organizational Citizenship Behaviors. Procedia Economics and Finance, 35(October 2015), 604-611. https://doi.org/10.1016/S2212-5671(16)00074-5

[37] Veličkovska, I. (2017). Organizational Citizenship Behavior-Definition, Determinants And Effects. Engineering management 3 (1) , 40-51.

[38] Wamy, N. j., \& Swamy. (2014). Leadership styles. Advances In Management Vol. 7 (1) January, 57-62.

[39] Winston, B. E., \& Patterson, K. (2006). An Integrative Definition of Leadership. International Journal of Leadership Studies, Vol. 1 Iss. 2, 6-66.

[40] Winston, B. E., \& Patterson, K. (2006). An Integrative Definition of Leadership. International Journal of Leadership Studies, Vol. 1 Iss. 2, 6-66.

[41] Yukl, G., \& Mahsud, R. (2010). WHY FLEXIBLE AND ADAPTIVE LEADERSHIP IS ESSENTIAL. Consulting Psychology Journal: Practice and Research, 62(2), 8193. https://doi.org/10.1037/a0019835

[42] Zeyada, M. (2018). Organizational Culture and its Impact On Organizational Citizenship Behavior. International Journal of Academic Research in Business and Social Sciences Vol 8 (3) March, 418-429. 